\title{
Efficiency and Productivity Analysis of the Saudi Manufacturing Industries
}

\author{
Dr. Mansour Abdullah Almiman \\ Department of Management Technology, Jeddah College of Technology, PO Box 17608, Jeddah 21494, Saudi \\ Arabia
}

\begin{abstract}
The measurement of total factor productivity for 24 manufacturing industries in Saudi Arabia between 2010 and 2016 is undertaken in the present study based on the Malmquist productivity index (MPI). Efficiency change and technical change are the two constituents of this index. According to the findings, technical efficiency enhancement was the main determinant of the productivity growth by an average of 1.063 percent across the examined industries. By contrast, regarding the rate of technological progress, the majority of the examined industries did not show a good rate of technological progress.
\end{abstract}

Keywords: Malmquist Index, total factor productivity, manufacturing industries, technical efficiency, technical change

DOI: $10.7176 / \mathrm{EJBM} / 11-6-14$

\section{Introduction}

The manufacturing sector is a key sector in the Saudi economy within the economy of Saudi Arabia, it represents the most extensive industry after mining and quarrying and it consists of businesses concerned mainly with the manufacture of new products through physical or chemical processing of materials or substances.. The new products may be finished or semi-finished. The geographical distribution of Saudi manufacturing industries shows that 40.4 percent of the manufacturing industries are concentrated in the middle region, with 22.4 percent and 22.1 percent accounting for the western and eastern regions respectively (General Authority for Statistics, 2016). The manufacturing industries in the middle region are food and beverages, textiles, chemical products, metal products, wood and its products and cement. The Eastern region contains most of the petrochemicals industries, cement, steel, fertilizers and oil refining. In the western region the manufacturing industrial activities are mainly food and beverages, paper products, metallic products and chemical products.

Table 1 shows that the share of manufacturing sector in real gross domestic product (GDP) grew steadily at the rate of 9.0 percent per annum in the period 1990-2016. The highest rate of 11.2 percent per annum was recorded in the period 2010-2016 (SAMA, 2017). Two main factors contributed to this increase. First, the country adopted a policy aimed at diversifying the country's economy and for this reason, the government has invested a large amount of capital in the manufacturing industries. At the same time the country devoted considerable effort to improve the quality of the workforce through various educational and vocational training. The manufacturing industry became the main body of the Saudi economy. Its role is very important and strategic as one of the main drivers for economic progress and the reduction in its overwhelming dependence on crude oil as a primary source of national income. Considering the importance of the manufacturing industries, this study measures the productivity change in the manufacturing industries in Saudi Arabia in recent years. Manufacturing industries are classified by the General Authority for Statistics according to the ISIC 2-digit.

Measuring and decomposing productivity change of the manufacturing sector plays an important role in helping plan economic development. However, only limited attempts have been made to measure and analyse productivity performance of this sector. Through the application of the non-parametric Malmquist productivity index (MPI) methodology, the study intends to cover a period of seven years. Using this approach, we disentangle effort to catch up the productivity, efficiency change, and technological change.

The paper is organised as follows. Section 2 reviews important studies that have contributed significantly to the literature on productivity measurement in general and in manufacturing industries in particular using the Malmquist approach. In Section 3, we provide the methodology and the framework of modeling and decomposition of productivity growth. Section 4 discusses information regarding data description and variables used. The empirical analysis and results are discussed in Section 5, concluding with Section 6. 
Table 1. Share of Manufacturing Sector in GDP

\begin{tabular}{|c|c|}
\hline Years & Percentage of GD \\
\hline $1990-2000$ & 7.3 \\
\hline $2000-2010$ & 8.7 \\
\hline $2010-2016$ & 11.2 \\
\hline $1990-2016$ & 9.0 \\
\hline
\end{tabular}

Source: Collected and calculated from data provided SAMA, Annual Report, 2016.

\section{Literature review}

Studies on productivity in Saudi Arabia in general and the manufacturing industrial sector are very little. The few studies on this industry are by Almiman (2002), Mousa (2017), Almosabbeh and Almoree (2018) among others. Using aggregate country level, Mousa (2017) estimated the Total Factor Productivity (TFP) for the Saudi economy from 1988 to 2014. The results show a fluctuation of the total factor productivity growth during the study period. The study suggested that the economy of Saudi Arabia needs an enhancement of its productivity based on catchingup the growth, specifically it needs an effective use of human resources, an increase in the number of skilled workers and the use of new technology. Despite the slight improvement in TFP growth, there are more obstacles facing the economic policy maker to improve the productivity of the Saudi economy. Specifically, the openness to MNC's, deregulating the labour market and focusing on Research and Development will have a great role in creating a faster TFP growth.

The Kaldor-Verdoorn and Thirlwall's laws were tested by Almosabbeh and Almoree (2018) to determine how manufacturing industry performance and economic development were correlated over the long term in Saudi Arabia. To that end, the authors relied on data from the World Bank, the Saudi Arabian Monetary Agency, the Penn World Table (PWT8) covering the period 1980-2014 as well as the five-year plan of the Saudi Ministry of Planning and National Economy. According to the results obtained, Kaldor's law applied to the Saudi data, although with reduced returns to scale and a coefficient of 0.83 . Similarly, Verdoorn's law applied at macro level with 0.81 elasticity coefficient and at sector level with 0.616 elasticity coefficient, with reduced returns to scale as well. Regarding Thirlwall's law, the correlation was the opposite of what was anticipated and the 0.599 elasticity coefficient was of significance.

Almiman (2002) investigated the productivity trends and technical efficiency performance of Saudi non-oil manufacturing industry. His study has four basic themes. First, it used growth accounting to calculate partial and TFP growth and analysed the sources of real output growth in the whole manufacturing industry, as well as in 31 and 9 branches classified as ISC 3-digit and 2-digit industries respectively. Second, it identified levels of TFP in 31 and 9 manufacturing industries by estimating a Cobb Douglas production function based on a fixed effects model. Third, it identified the technical efficiency levels in the manufacturing industries by estimating a stochastic frontier translog production function based on panel data consisting of 31 and 9 sectors. The study applied the econometrics model to estimate the TFP. The results derived from the econometric estimation of the levels of TFP suggest that the structure of the Saudi manufacturing industries is characterised by a constant return to scale.

Although there is minimal literature on productivity analyses in the Saudi manufacturing sector, there have been numerous studies conducted on productivity growth at the international level. Among these studies we can mention the non-parametric approach based on the Malmquist productivity index. Joshi and Singh (2010) measured the TFP and identified its sources through applying a non-parametric DEA-based MPI approach. Through this approach, the productivity growth was decomposed into technical efficiency change and technological change. Further, an attempt had also been made to study the variation in the productivity growth rates across location, scale-size and type of garments.

The MPI was used by Saravanakumar and Kim (2012) to assess the increase in total factor productivity and its elements within the manufacturing industries in India, both before and after reforms. The findings revealed that manufacturing industries in India did not become more productive as a result of reforms in economy, although the latter did not have the same effects in all industries and in the elements of total factor productivity. For instance, heavy industries became more productive but light industries became less productive post-reforms. Furthermore, efficiency and technological progress were aided by reforms in heavy industries but not in light industries. The conclusion drawn was that productivity increase in the long term required the implementation of relevant policies to boost both efficiency and technological progress.

TFPG and its elements in ten Indian manufacturing industries were the focus of the investigation by Manjappa and Mahesha (2008). Based on yearly time series data from 1994-2014, the selected industries were equally divided into capital-intensive and labour-intensive industries. By using the MPI on panel data, it was found that there was 
a moderate annual increase of 1.7 percent in the average TFPG associated with capital-intensive industries. By contrast, the productivity of the labour-intensive industries declined over the analysed period.

The MPI was assembled by Ray (2002) based on nonparametric linear programming techniques. The author employed data from 1986-1987 and 1995-1996 to measure the yearly change rates of productivity and technical efficiency among manufacturing industries in different Indian states. The findings indicated that, during the 1990s, productivity increased more per year than during the previous decade, yet in certain states, productivity slowed down or even decreased during the 1990s. However, the author did not include any index in the MPI breakdown to indicate the impact of biased technical change on productivity change.

In a different study, Ray and Mukherjee (2005) adopted the DEA approach and the Tornquist and Malmquist index to respectively assess technical efficiency and productivity in specific states in India. According to the results, both techniques revealed that the yearly rate of productivity increase was greater after reforms than before reforms, although productivity did decline after reforms in certain states, including Assam, Himachal Pradesh and Orissa. As indicated by the MPI breakdown, the growth intensification was due to the enhanced technical efficiency combined with quicker technical progress.

There are many studies on productivity analysis of the manufacturing sectors at the international level. But one could find that these studies vary widely depending upon the methodology used. As discussed above, there are few studies conducted so far to measure the productivity performance of the Saudi industry both at aggregate and disaggregate levels.

\section{Methodology}

\subsection{Total Factor Productivity and it's Measurement}

Productivity theory has been accompanied by the development of economic growth theories and has evolved through emphasis on the concepts of single factor productivity and total factor productivity (TFP). Single factor productivity refers to the measurement of productivity that is a ratio of total output and a single input factor. It does not answer the contribution of various elements to total productivity, coupled with the fact that technological innovation has been playing a more important role in economic growth. Hence it faces challenges from both theoretical and empirical aspects (Lovell \& Schmidt, 1993). In contrast, TFP measures the ratio of total output and all the input factors invested. It is often regarded as a broad indicator of technological progress and has been widely used in economic growth measurement. TFP changes or improvements can also be seen as real cost reductions that have important implications for growth (Harberger, 1998). Tinbergen (1942) is the earliest scholar proposing the concept of TFP and introduces a time variable into the Cobb-Douglas production function. Later, Stigler (1947) used TFP in measuring manufacturing productivity in the U.S. Davis (1955) defined the concept of TFP and highlighted that TFP measured productivity by including all inputs. Based on the Cobb-Douglas production function, Solow (1957) introduced a way to calculate TFP with the assumptions of neutral technology, constant returns to scale and named it technological progress. Based on the Solow Model, Fabricant (1959) and Denison (1962) further developed TFP theory with emphasis on embodied and disembodied technological progress. Jorgenson and Nishimizu (1967) extended the Solow Model in empirically investigating American and Japanese TFP and pointed out that the source of TFP came from technological progress and measurement bias. Technological progress alongside technical efficiency also plays an important role in economic growth (Farrell, 1957). It is well known that during the production process, desirable outputs were produced alongside undesirable outputs, such as waste water and air pollution. However, traditional measurements of TFP growth only consider desirable outputs and ignore undesirable outputs, which inevitably overestimate the productivity growth if undesirable outputs are ignored (Chung et al., 1997; Hailu \& Veeman, 2000; Fare et al., 2001; Kumar, 2006; Zhang et al., 2011).

Nishimizu and Page (1982) first proposed the decomposition framework of TFP. According to the empirical research, the concept of TFP growth is more widely used than TFP itself. Lucas (1988) divided TFP growth into two parts, technological progress and technical efficiency, which represented the movement of a production frontier and improvement of efficiency, respectively. It has been widely used in empirical research since then. Further, technical efficiency can be divided into pure technical efficiency and scale efficiency. Pure technical efficiency includes institutional innovation and management experiences accumulation. Scale efficiency presents economies of scale of enterprises (Fare et al., 1994b; Battese \& Coelli, 1995; Kumbhakar, 1996; Kumbhakar et al., 2000; Karagiannis et al., 2002).

Several methods are used to measure the potential contribution of the change in efficiency to the productivity-level variations, and they can be classified into two main groups: parametric models using particular specifications to characterise technology in order to estimate either constant coefficients or parametric equations of technical change. Unlike parametric models, Data Envelopment Analysis (DEA) introduced by Charnes et al. (1978) and generalized 
by Banker et al. (1984) offers a non-parametric alternative to parametric frontier production analysis. DEA estimates the Malmquist productivity index (MPI) and decomposes the Malmquist productivity change index into multiplicative factors such as efficiency change and technological change. The study uses DEA-based MPI to measure productivity change (TFP) over a period of time.

\subsection{Malmquist Index of Productivity}

Caves et al. (1982) introduced the Malmquist productivity index in order to measure the total factor productivity from inputs and multiple outputs technology. The underlying reasons of this choice can be presented in three elements. First, this index is calculated using data based on quantities only. It is a significant advantage when information about prices is not available or when prices are biased. Therefore, this index is based on weak behavioural assumptions. Finally, when the panel data are available, the Malmquist index provides a simple decomposition of the productivity change into a technical efficiency improvement and a technological progress. Consequently, this study has applied this already extensively utilised technique to estimate the TFP growth and its components within the area of the Saudi manufacturing industries.

Malmquist indexes are constructed from the ratios of distance functions. In the current study, the Malmquist index is calculated based on Shephard (1953) input-oriented distance functions because we have to find out the trends of input reductions achieved without deteriorating the output levels. Shephard distance functions are the inverse of the Farrell (1957) measure of technical efficiency and can be obtained from the optimal solution of the constant return to scale (CRS) model. Following Fare et al. (1994), under the assumption of constant returns to scale, outputoriented TFP change can be denoted as follows:

$$
\begin{gathered}
M_{o}=\left(\frac{\phi_{o}^{t}\left(x_{o}^{t+1}, y_{o}^{t+1}\right)}{\phi_{o}^{t}\left(x_{o}^{t}, y_{o}^{t}\right)} \cdot \frac{\phi_{o}^{t}\left(x_{o}^{t+1}, y_{o}^{t+1}\right)}{\phi_{o}^{t+1}\left(x_{o}^{t}, y_{o}^{t}\right)+}\right)^{1 / 2} \\
M_{o}=\left(\frac{\phi_{o}^{t+1}\left(x_{o}^{t+1}, y_{o}^{t+1}\right)}{\phi_{o}^{t}\left(x_{o}^{t}, y_{o}^{t}\right)}\right) \cdot\left(\frac{\phi_{o}^{t}\left(x_{o}^{t+1}, y_{o}^{t+1}\right)}{\phi_{o}^{t+1}\left(x_{o}^{t+1}, y_{o}^{t+1}\right)} \cdot \frac{\phi_{o}^{t}\left(x_{o}^{t}, y_{o}^{t}\right)}{\phi_{o}^{t+1}\left(x_{o}^{t}, y_{o}^{t}\right)+}\right)^{1 / 2}
\end{gathered}
$$

Where $M_{o}$ measures the productivity change between period $t$ and $t+1$. Productivity improves if $M_{o}>1$, remains unchanged if $M_{o}=1$, and declines if $M_{o}<1$. $\phi_{o}$ is the efficiency; $x_{o}$ is the input; $y_{o}$ is the output. The first term on the right-hand side measures the magnitude of the efficiency change between period $t$ and $t+1$.

$$
T E C_{o}=\left(\frac{\phi_{o}^{t+1}\left(x_{o}^{t+1}, y_{o}^{t+1}\right)}{\phi_{o}^{t}\left(x_{o}^{t}, y_{o}^{t}\right)}\right)
$$

$T E C_{o}>1$, Technical efficiency improves.

$T E C_{o}=1$, Technical efficiency remains the same

$T E C_{o}<1$, Technical efficiency declines.

The second term $F S_{o}$ measures the change in the Frontier (Technology change) between period $t$ and $t+1$.

$$
F S_{o}=\left(\frac{\phi_{o}^{t}\left(x_{o}^{t+1}, y_{o}^{t+1}\right)}{\phi_{o}^{t+1}\left(x_{o}^{t+1}, y_{o}^{t+1}\right)} \cdot \frac{\phi_{o}^{t}\left(x_{o}^{t}, y_{o}^{t}\right)}{\phi_{o}^{t+1}\left(x_{o}^{t}, y_{o}^{t}\right)}\right)^{1 / 2}
$$

$F S_{o}>1$, indicates progress in Frontier technology

$F S_{o}=1$, no shift in the Frontier technology

$F S_{o}<1$, indicates regress in Frontier technology

The Malmquist productivity change can be expressed as

$$
\begin{gathered}
\mathrm{M}_{\mathrm{o}}=\mathrm{TEC}_{\mathrm{o}} \times \mathrm{FS}_{0} \\
\mathrm{TEC}_{\mathrm{o}}=\mathrm{PTEC} \times \mathrm{SEC}
\end{gathered}
$$

Where PTEC the efficiency change calculated under VRS and can be defined as:

$$
\text { PTEC }=\left(\frac{\phi_{o V R S}^{t+1}\left(x_{o}^{t+1}, y_{o}^{t+1}\right)}{\phi_{o V R S}^{t}\left(x_{o}^{t}, y_{o}^{t}\right)}\right)
$$

While the $T E C_{o}$ represents the changes in technical efficiency calculated under CRS, the PTEC corresponds to changes in the technical efficiency with regard to VRS and represents the changes resulting from efficiency improvements in operations and management activities. 
$S E C$ represents the scale efficiency:

\section{Data description}

$$
S E C=\left(\frac{\phi_{o C R S}^{t+1}\left(x_{o}^{t+1}, y_{o}^{t+1}\right) / \phi_{o V R S}^{t+1}\left(x_{o}^{t+1}, y_{o}^{t+1}\right)}{\phi_{o C R S}^{t}\left(x_{o}^{t}, y_{o}^{t}\right) / \phi_{o V R S}^{t}\left(x_{o}^{t}, y_{o}^{t}\right)}\right)
$$

This study covers the period from 2010-2016 and the principle data source is Annual Survey reports published by the General Authority for Statistics in Saudi Arabia. The Industrial Survey Reports considers only registered manufacturing sectors and covers only the organised segment of Saudi manufacturing, i.e. those factories which employ lees than 5 or more workers with power and 20 or more workers. In the ASTI, the manufacturing industries are classified under 24 sectors, at two-digit industrial classification levels. In this study, the revenues were taken as a measure of output whereas the inputs were regarded as labour and capital. The total number of persons engaged in industrial units is taken as the measure of labor input. Gross capital is taken as the measure of capital input.

Table 2 provides summary statistics including means, medians and standard deviations for the input and output variables used in this study. The fact that all variables have a mean value larger than the median indicates that the distributions of all the variables are skewed to the right. This means that a large number of manufacturing industries have operated with small inputs and small output levels, and a relatively few sectors have operated with large inputs and output levels. The skewness of revenue, capital and labour variables are 3, 4 and 1, respectively.

Table 2. Descriptive Analysis of the Variables

\begin{tabular}{|l|c|c|c|}
\hline Designation & Y & K & L \\
\hline Mean & 2214697 & 2664928 & 34876 \\
\hline Median & 9538549 & 839579 & 20960 \\
\hline Maximum & 169316595 & 35934878 & 138581 \\
\hline Minimum & 6870 & 643 & 160 \\
\hline Standard Deviation & 34960468 & 4960206 & 36204 \\
\hline Skewness & 3 & 4 & 1 \\
\hline Kurtosis & 6 & 18 & 1 \\
\hline
\end{tabular}

Source: Author's calculation.

\section{Empirical Results}

This section presents the results obtained from the Malmquist TFP index for the Saudi manufacturing industries. The findings are decomposed into pure efficiency change, frontier change (technical change) and scale efficiency change.

As shown in Table 3, the scale efficiency change and pure technical change improved in the majority of industries by 67percent, with efficiency change and technical change of 50 percent. Nonetheless, between 2010 and 2013 , the majority of changes worsened. By contrast, there was a 6.4 percent decrease in technological change. Different MPIs indicated that productivity change improved with 31.95percent efficiency change, 3.1 percent pure efficiency change and 10.26 percent total factor productivity change.

Technological change declined the most (39.5percent) in 2012-2013, whereas in the same period, enhancement in technical efficiency change led to a significant increase in total factor productivity change. Likewise, technical efficiency change and efficiency change increased by 0.8percent and 0.3percent, respectively, in 2015-2016. Thus, owing to scale efficiency enhancement, technical efficiency improvement was achieved by the majority of industries.

Table 4 provides details of the examination of 24 manufacturing industries, highlighting that TFP increase in the research period was achieved by 14 industries, namely, food products, beverages, textiles, clothing, wood and products of wood and cork, printing and reproduction of recorded media, chemicals and chemical products, pharmaceutical products and preparations, other non-metallic mineral products, basic metals, furniture, as well as machinery and equipment repair and installation. Efficiency change was the major driver that made those industries more productive. In the case of manufacturing of tobacco products and fabricated metal products, technological 
change also promoted increase in productivity, alongside efficiency change. Furthermore, of the 14 industries, the greatest and lowest annual increases of 110.6 percent and 0.88 percent were respectively achieved by clothing manufacturing, owing to the efficiency change element of 195.5 percent, and by manufacturing of computer, electronic and optical products, owing to efficiency change and technological change. Efficiency change breakdown revealed that the scale efficiency change and pure efficiency change amounted to 7.8 percent and 110.9 percent, respectively. By contrast, the TFP growth rate of the remaining ten industries was negative. As previously mentioned, the lowest TFP index was associated with manufacturing of computer, electronic and optical products, which decreased primarily as a result of technological change of 5.8 percent. Table 3 outlines TFP breakdown, clearly showing that the lower TFP index exhibited by some manufacturing industries was mainly the outcome of technological change downturn.

In order to study the productivity change of perspective years, we have shown in Figure 1 the distribution of total factor productivity growth over the period (2011-2016). Figure 1 shows that manufacture of chemicals and chemical products and that of pharmaceutical products and preparations registered positive TFP growth over the studied periods which is manly explained by efficiency change component. The manufacturing of wearing apparel registered maximum positive TFP growth (8.4 percent) in 2012-2013, while the same industry shows the highest negative TFP growth (0.124 percent) in 2011-2012. During the period (2012-2013), it is evident that 83 percent of the industries performed well with positive TFP growth and exhibited that TFP index values is exceeded by one. The productivity growth in these industries is achieved either through the introduction of best operating and management practices of industry or adoption new technology such as installation of more efficient machines and tools. The yearly distribution of TFP indices clearly reveals that the manufacturing industries are having wide fluctuations during the period of investigation, although they have been able to increase their overall productivity but unable to maintain their growth yearly. For example, the manufacture of wearing apparel has productivity growth over the entire period but was unable to manage its growth in 2011-2012 and in 2014-2015. Such fluctuations are not abnormal in DEA studies, since the DEA method is data sensitive. The reasons for fluctuation in input data may be due to improper operations and outdated technology which leads to a fall in levels of efficiency and productivity of industries.

Table. 3 Annual Geometric Mean of TFP and its Components

\begin{tabular}{|c|c|c|c|c|c|}
\hline Year & TFPCH & EFFCH & TECHCH & SECH & PECH \\
\hline $2010-211$ & 0.990 & 0.996 & 0.993 & 1.080 & 0.988 \\
\hline $2011-212$ & 0.939 & 0.910 & 1.036 & 1.084 & 1.474 \\
\hline $2012-213$ & 1.680 & 2.783 & 0.605 & 0.914 & 0.590 \\
\hline $2013-214$ & 0.908 & 1.238 & 0.842 & 1.303 & 1.094 \\
\hline $2014-215$ & 1.110 & 0.978 & 1.137 & 1.008 & 1.032 \\
\hline $2015-216$ & 1.010 & 1.008 & 1.003 & 0.989 & 1.007 \\
\hline Mean & $\mathbf{1 . 1 0 6}$ & $\mathbf{1 . 3 1 9}$ & $\mathbf{0 . 9 3 6}$ & $\mathbf{1 . 0 6 3}$ & $\mathbf{1 . 0 3 1}$ \\
\hline & TFPCH $<1=3$ & EFFCH $<1=3$ & TECHCH $<1=3$ & SECH $<1=2$ & PECH $1<=2$ \\
& TFPCH $>1=3$ & EFFCH $1>=3$ & TECHCH $>1=3$ & SECH $>1=4$ & PECH $>1=4$ \\
& TFPCH $=1=0$ & EFFCH $=1=0$ & TECHCH $=1=0$ & SECH $=1=0$ & PECH $=1=0$ \\
\hline
\end{tabular}

Notes: TFPCH - total factor; EFFCH - efficiency change; TECHCH - technical change; SECH - scale efficiency change; $\mathrm{PECH}$ - pure technical efficiency change.

Table 4. Malmquist Index Summary of Sector Means 2010-2016

\begin{tabular}{|l|r|r|r|r|c|}
\hline \multicolumn{1}{|c|}{ Manufacturing Industry } & TFPCH & EFFCH & TECHCH & SECH & PECH \\
\hline food products & 1.043 & 1.240 & 0.936 & 0.952 & 0.953 \\
\hline beverages & 1.059 & 1.147 & 0.966 & 1.010 & 1.102 \\
\hline tobacco products & 1.411 & 1.371 & 1.048 & 1.986 & 1.000 \\
\hline textiles & 1.060 & 1.265 & 0.924 & 1.000 & 0.859 \\
\hline wearing apparel & 2.106 & 2.951 & 0.971 & 1.078 & 2.109 \\
\hline leather and related products & 0.917 & 0.944 & 0.931 & 0.991 & 0.848 \\
\hline wood and of products of wood and cork & 1.187 & 1.524 & 0.962 & 1.004 & 1.054 \\
\hline paper and paper products & 0.963 & 1.129 & 0.879 & 1.000 & 0.786 \\
\hline $\begin{array}{l}\text { Printing and reproduction of recorded } \\
\text { media }\end{array}$ & 1.032 & 1.193 & 0.950 & 1.000 & 0.931 \\
\hline
\end{tabular}




\begin{tabular}{|c|c|c|c|c|c|}
\hline coke and refined petroleum products & 0.943 & 1.359 & 0.836 & 1.000 & 1.000 \\
\hline chemicals and chemical products & 1.203 & 1.964 & 0.796 & 1.047 & 1.000 \\
\hline products and preparations pharmaceutical & 1.086 & 1.165 & 0.970 & 1.002 & 1.254 \\
\hline rubber and plastics products & 0.991 & 1.189 & 0.923 & 1.004 & 0.831 \\
\hline other non-metallic mineral products & 1.567 & 1.891 & 0.924 & 1.335 & 1.072 \\
\hline basic metals & 1.097 & 1.202 & 0.983 & 1.001 & 0.869 \\
\hline fabricated metal products & 1.100 & 1.214 & 1.003 & 1.054 & 0.878 \\
\hline computer, electronic and optical products & 0.883 & 0.958 & 0.942 & 1.003 & 1.059 \\
\hline electrical equipment & 0.937 & 1.044 & 0.896 & 0.965 & 0.827 \\
\hline machinery and equipment n.e.c. & 0.933 & 1.110 & 0.908 & 0.972 & 0.845 \\
\hline motor vehicles, trailers and semi-trailers & 0.986 & 1.160 & 0.951 & 1.001 & 0.990 \\
\hline other transport equipment & 0.971 & 1.156 & 0.896 & 1.002 & 1.080 \\
\hline furniture & 1.120 & 1.372 & 0.965 & 1.051 & 0.959 \\
\hline Other manufacturing & 0.868 & 0.935 & 0.925 & 1.002 & 0.993 \\
\hline $\begin{array}{l}\text { Repair and installation of machinery and } \\
\text { equipment }\end{array}$ & 1.082 & 1.173 & 0.980 & 1.053 & 1.444 \\
\hline Average & 1.106 & 1.319 & 0.936 & 1.063 & 1.031 \\
\hline
\end{tabular}

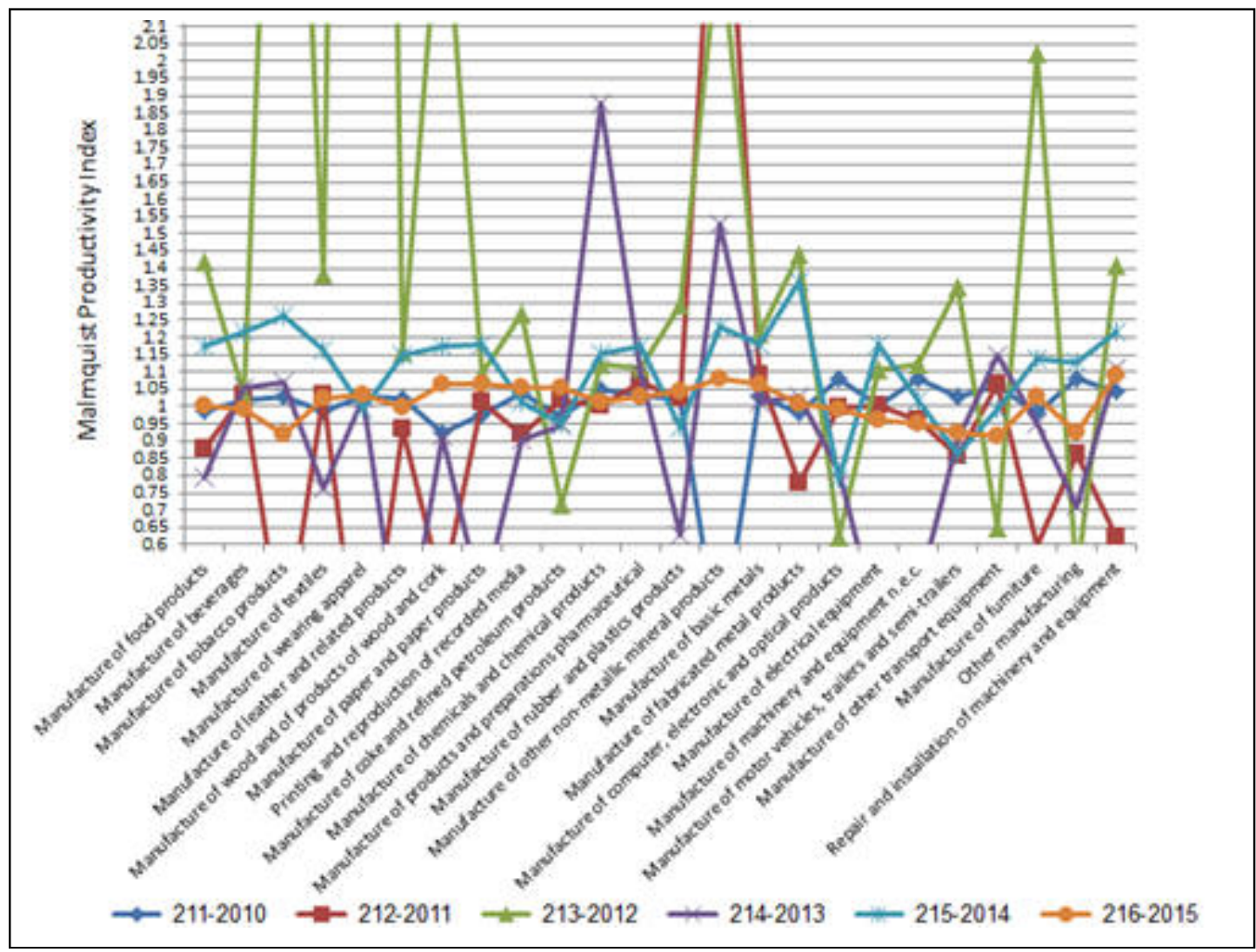

Figure 1. Productivity change in manufacturing industries

\section{Conclusion}

This study investigated productivity, technical change and technical efficiency of 24 manufacturing industries in Saudi Arabia over the period 2010-2016. The Malmquist index enabled the sources of TFP change to be decomposed into pure efficiency change, scale efficiency change and technical change. The study finds that mean TFP growth for the whole manufacturing industries is quite high. This growth had been the result of efficiency improvements. The change in the technological level was, on the other hand, poor. Moreover, the scale efficiency 
has increased by 6.3 percent on average. Sector-wise analysis shows that the 14 sectors, out of 24 sectors, achieve positive growth in TFPG and remaining sectors experienced negative growth in TFP over the whole period. Productivity of manufacturing industries mainly declined due to technological change rather than efficiency change. The result of productivity distribution analysis shows that more than 83 percent of sectors performed well with positive TFP growth in the year 2012-2013. The most successful sector of TFPG is that of the manufacture of wearing apparel, its improvement reflected by its relatively high efficiency change score. In the conclusion, the negative productivity growth is a matter of concern and needs further analysis to expose the exact cause of negative productivity which would help the policy makers and industrial planners.

\section{References}

Almiman, M. (2002). Productivity Performance in the Saudi Non-Oil Manufacturing Industries, PhD Dissertation, University of Manchester, Manchester.

Almosabbeh, I. \& Almoree, A. (2018). The Relationship between Manufacturing Production and Economic Growth in the Kingdom of Saudi Arabia. Journal of Economic Studies, 45(4), 674-690.

Banker, R.D., Charnes, A. \& Cooper, W.W. (1984). Some Models for Estimating Technical and Scale Efficiencies in Data Envelopment Analysis. Management Science, 30(9), 1078-1092.

Battese, G. E., \& Coelli, T. J. (1995). A model for technical inefficiency effects in a stochastic frontier production function for panel data. Empirical Economics, 20 (2), 325-332.

Caves, D. W., Christensen, L. R. \& Diewert, W. E. (1982). The economic theory of index numbers and the measurement of input, output, and productivity. Econometrica, 50(6), 1393-1414.

Charnes, A., Cooper, W.W. \& Rhodes, E. (1978). Measuring the Efficiency of Decision Making Units. European Journal of Operation Research, 2(6), 429-444.

Chung, Y. H., Fare, R. \& Grosskopf, S. (1997). Productivity and undesirable outputs: A directional distance function approach. Journal of Environmental Management, 51(3), 229-240.

Denison E. (1962). Sources of Economic Growth in the United States and the Alternatives before the US, New York, Committee for Economic Development.

Fabricant, S. (1959). Basic Facts on Productivity Change. Occasional Paper no. 63, New York, National Bureau of Economic Research.

Fare, R., Grosskopf, S. \& Pasurka, C. A. (2001). Accounting for air pollution emissions in measures of state manufacturing productivity growth. Journal of Regional Science, 41(3), 381-409.

Fare, R., Grosskopf, S., Norris, M. \& Zhang, Z. (1994). Productivity growth, technical progress, and efficiency change in industrialized countries. American Economic Review, 84(1), 66-83.

Farrell, M.J. (1957).“The Measurement of Productive Efficiency. Journal of the Royal Statistical Society, Series A, 120(3), 253-290.

General Authority for Statistics - Saudi Arabia. (2010,2011, 2012,2013,2014,2015, 2016). Industrial Survey Reports, Riyadh, General Authority for Statistics.

Hailu, A. \& Veeman, T. S. (2000). Environmentally sensitive productivity analysis of the Canadian pulp industry. Journal of Environmental Economics and Management, 40(3), 251-274.

Harberger, A. C. (1998). A Vision of the Growth Process, Presidential Address, American Economic Association. American Economic Review, 88(1), 1-32.

Jorgenson, D. W. \& Nishirnizu, M. (1978). U.S. and Japanese economic growth, 1952-1974: An international comparison". Economic Journal, 88(352), 707-726.

Joshi, R.N. \& Singh, S.P. (2010). Estimation of total factor productivity in the Indian garment industry. Journal of Fashion Marketing and Management, 14(1), 145-160.

Karagiannis, G., Midmore, P. \& Tzouvelekas, V. (2002). Separating technical change from time-varying technical inefficiency in the absence of distributional assumptions. Journal of Production Analysis, 18(1), 23-38.

Kumar, S. (2006). Environmentally sensitive productivity growth: A Global analysis using Malmquist-Luenberger index. Ecological Economics, 56(2), 20-293.

Kumbhakar, S. C. (1996). Efficiency measurement with multiple outputs and multiple Inputs. Journal of 
Productivity Analysis, 7(2), 225-255.

Kumbhakar, S. C., Denny, M. \& Fuss, M. (2000). Estimation and decomposition of productivity change when production is not efficient: A panel data approach. Econometric Reviews, 19(4), 213-320.

Lovell C.A.K. (1993).Production Frontiers and Productive Efficiency. in Fried HO and SS Schmidt (eds.) the Measurement of Productive Efficiency: Techniques and Applications, Oxford University Press, New York, 3-67.

Lucas, Robert E. Jr. (1988). On the Mechanics of Economic Development. Journal of Monetary Economics, 22(1), $3-42$.

Manjappa, D.H. \& Mahesha, M. (2008).Measurement of productivity growth, efficiency change and technical progress of selected capital-intensive and labour-intensive industries during reform period in India. Indian Journal of Economics and Business, 5(4), 57-65.

Mousa, W (2017). Estimating Total Factor Productivity of Saudi Economy, paper presented at the International Research Conference, October 2017, Las Vegas (unpublished paper).

Nishimizu, M. \& J. Page (1982). Total Factor Productivity Growth, Technological Progress and Technical Efficiency Change: Dimensions of Productivity Change in Yugoslavia, 1965-1978. The Economic Journal, 92(368), 920-936.

Ray, S. C. (2002). Did India's economic reforms improve efficiency and productivity? A nonparametric analysis of the initial evidence from manufacturing. Indian Economic Review, 37(1), 23-57.

Ray, S. C. \& Mukherjee, Kankana. (2005). Technical Efficiency and its Dynamics inIndian Manufacturing: An Inter-state Analysis. .Indian Economic Review, 40(2), 101-125.

Saravanakumar, M. \& Kim, T. (2012). The Impacts of Economic Reforms on Efficiency Improvement and Technological Progress in Indian Manufacturing. The Journal of Developing Areas, 46(1), 315-329.

Saudi Arabian Monetary Agency. (2017). Annual Reports, Riyadh, Research and Statistics Department.

Shepard, R. W. (1953). Cost and production functions. Princeton, New Jersey: Princeton University Press. 104 p.

Solow, R.M. (1957). Technical Change and the Aggregate Production Function. Review of Economics and Statistics, 39(3), 312-320.

Stigler, G. J. (1947). Trends in output and employment. New York: National Bureau of Economic Research.

Tinbergen, J. (1942). On the Theory of Trend Movements, in Klassen, L., Koyck, L. and H. Witteveen, Amsterdam, North Holland.

Zhang, C., Liu, H., Bressers, H. T. \& Buchanan, K. S. (2011). Productivity growth and environmental regulationsaccounting for undesirable outputs: Analysis of China's thirty provincial regions using the Malmquist-Luenberger index. Ecological Economics, 70, 2369-2379. 